\title{
Ligand Exchange Kinetics of 2,2'-Bipyridine with Nitrilotriacetatonickelate(II)
}

\author{
Shelby Coleman ${ }^{a}$ and Dr. Larry Kolopajlo ${ }^{a}$
}

The kinetics of the ligand exchange reaction between 2,2'-bipyridine (bipy) and NiNTA' was studied over the pH range 4.7 to 7.5 at $25.0^{\circ} \mathrm{C}$ and an ionic strength of $0.10 \mathrm{M}$ by following the formation of $\mathrm{Ni}$ (bipy) 3 product at $307 \mathrm{~nm}$. All reactions were run under pseudo-first order conditions with a [bipy]/[NiNTA $]$ ratio of at least 20. The reaction is first-order with respect to each of NiNTA ${ }^{-}$ and to bipy. The reaction is also accelerated by hydrogen ion. The rate constant for the hydrogen ion unassisted addition of bipy to NiNTA- is $\mathrm{k}_{\text {bipy }}^{\mathrm{Ni}(\mathrm{NTA}) \text { bipy }}=0.671 \mathrm{M}^{-1} \mathrm{~s}^{-1}$. The reaction is also first-order in hydrogen ion with a rate constant for the hydrogen ion assisted addition of bipy to NiNTA- of $\mathrm{k}_{\mathrm{H} \text {,bipy }}^{\mathrm{Ni}(\mathrm{NTA}) \text { bipy }}=9.45 \times 10^{4} \mathrm{M}^{-2} \mathrm{~s}^{-1}$. A dissociative type mechanism accelerated by hydrogen ion is proposed. The work has significance by showing that NiEDDA and NiNTA, both aminopolyacrboxylate complexes react by the same mechanism.

Keywords: Kinetics, ligand exchange, ligand substitution, 2,2'-bipyridine, NiNTA

\section{Introduction}

Ligand substitution reactions of nickel(II) complexes (NiL) ordinarily follow dissociative type mechanisms and are generally accelerated by hydrogen ion ${ }^{1,2}$. When a sufficient number of coordination sites in the nickel complex reactant are initially water solvated, reactions with bidentate ligands $\left(\mathrm{B}_{2}\right)$ involve the rapid formation of a ternary complex (1) followed by a slower ligand exchange (2):

(1) $\quad \mathrm{NiL}+\mathrm{B}_{2} \rightarrow \mathrm{Ni}(\mathrm{L})\left(\mathrm{B}_{2}\right)$

(2) $\mathrm{Ni}(\mathrm{L})\left(\mathrm{B}_{2}\right)+2 \mathrm{~B}_{2} \rightarrow \mathrm{Ni}\left(\mathrm{B}_{2}\right)_{3}+\mathrm{L}$

Numerous studies ${ }^{3-6}$ have examined the effects that coordinated multidentate ligands exert on the formation of ternary complexes, but fewer have described analogous effects in ligand exchange reactions. Steinhaus ${ }^{7}$ found that the NiEDDA-1,10-phenanthroline ligand exchange reaction followed a mechanism in which phen coordinates to a partially unwrapped NiEDDA species whereas the $\mathrm{Ni}(\text { trien })^{2+}$-phen reaction ${ }^{8}$ showed that trien completely dissociated before phen was able to coordinate. Coordinated phen did not alter the dissociation of EDDA from $\mathrm{Ni}(\mathrm{EDDA})(\mathrm{phen})$ but it accelerated the dissociation of trien from $\mathrm{Ni}($ trien)(phen) by a factor of 200 times that of $\mathrm{Ni}(\text { trien })^{2+}$. In previously reported work on NTA, Cassatt ${ }^{9}$ reported that the ternary complex formation of NiNTA ${ }^{-}$with phen was slightly faster than with bipy and that Hbipy ${ }^{+}$reacted with NiNTA $^{-}$while $\mathrm{Hphen}^{+}$did not. Bydlaek ${ }^{10}$ studied the metal exchange reaction between $\mathrm{NiNTA}^{-}$and $\mathrm{Cu}^{2+}$ and found that the reaction was first-order in each reactant and in hydrogen ion. Another study ${ }^{11}$ followed

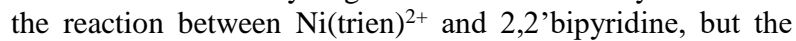
mechanism was not fully elucidated. Moreover, Kolopajlo et $\mathrm{al}^{12}$ reported the reaction between $\mathrm{Ni}$ (tetren) ${ }^{2+}$ and 2,2'bipyridine and found that it was second-order overall, and followed a linear dependence of rate constant versus hydrogen ion concentration as reported for the NiEDDA-bipy reaction; the mechanism followed a proton assisted pathway.
This report adds to the previous work done on NTA by investigating the ligand exchange reaction of $\mathrm{NiNTA}^{-}$with bipy. It examines the kinetic effect of replacing an amine group in EDDA with an acetate group to give NTA whose corresponding NiNTA- complex then contains three labile dentate sites compared to two in EDDA.

Aside from adding to the knowledge base of coordination chemistry kinetics, another reason for studying this reaction is that NTA is released into the environment, mainly through its many industrial and commercial uses. For example, because NTA is a better chelating agent than phosphate for both calcium and magnesium, it is used as a green water softening agent to substitute for sodium and potassium triphosphates in detergents and cleansers ${ }^{13}$. In another commercial use, NTA is used to extract arsenic, chromium, and copper from wood preserved with heavy metal arsenates ${ }^{14}$. On the other hand, nickel is also released to the environment from numerous anthropogenic and natural sources ${ }^{15}$, and is generally considered to exist at a concentration less than $10 \mu \mathrm{g} / \mathrm{L}$ in drinking water ${ }^{16}$.

\section{Experimental} Reagents

High purity reagents (> 99\%) from Aldrich Corp. were used. Nitrilotriacetic acid (Sigma grade, $\geq 99.0 \%$ ), and nickel(II) hexahydrate $(99.999 \%)$, were used to prepare NiNTA'. MES buffer (2-(N-morpholino)ethanesulfonic acid, $\geq 99.5 \%$ ) was employed over the $\mathrm{pH}$ range 5.5 to 6.7 while HEPES buffer (4-(2-Hydroxyethyl)piperazine-1ethanesulfonic acid, $\geq 99.5 \%$ ) was used for reactions from $\mathrm{pH}$ 6.8 to 8.2. Water was doubly distilled and passed through a Millipore Nanopure water purification system before use. All 2,2'-bipyridine solutions were stored in the dark because they are light sensitive.

Safety

The safety precautions associated with $\mathrm{NTA}^{17}$ and nickel $^{18}$ are readily found. Workers should avoid skin contact 
with 2,2'-bipyridine and NTA. Nickel nitrate is a strong oxidizer and must be stored properly. Most importantly, sodium cyanide ${ }^{19}$, used in the preparation of NiNTA described below, is lethal, and must be contained at all times in a fume hood. Because on contact with acid, it liberates hydrogen cyanide gas which is also lethal, its solutions must be maintained at $\mathrm{pH}>10$. Moreover, students should not handle or perform any procedures using $\mathrm{NaCN}$.

Preparation and Standardization of NiNTA

The nickel-nitrilotriacetate complex was prepared using known procedures ${ }^{20}$ by adding a slight excess of $\mathrm{Ni}\left(\mathrm{NO}_{3}\right)_{2}$ to a solution of nitrilotriactetic acid with a ratio of nickel to $\mathrm{NTA}^{3-}$ slightly above one:

(3) $\mathrm{Ni}^{2+}(\mathrm{aq})+\mathrm{NTA}^{3-}(\mathrm{aq}) \rightarrow \mathrm{Ni}(\mathrm{NTA})^{-}(\mathrm{aq})$

The reaction was allowed to proceed while the $\mathrm{pH}$ was gradually raised to about 12 using $\mathrm{NaOH}$. Excess nickel was filtered off as the hydroxide using a 0.1 micron Millipore filter and the $\mathrm{pH}$ of the resulting complex was lowered to the range 6 to 7 for storage. The solutions were standardized by adding excess cyanide at $\mathrm{pH} 9$ and measuring the concentration of $\mathrm{Ni}(\mathrm{CN}) 4^{2-}$ at $267 \mathrm{~nm}$.

\section{Procedure for Kinetic Runs}

All kinetic measurements were carried out at $25.0{ }^{\circ} \mathrm{C}$, at an ionic strength $(\mu)$ of $0.10 \mathrm{M}$, and within the $\mathrm{pH}$ range 4.7 to 7.5 with the addition of MES or HEPES buffer, both noncomplexing reagents. The final solution $\mathrm{pH}$ was adjusted with sodium hydroxide or hydrochloric acid while the ionic strength of all reaction mixtures was controlled using sodium chloride. An Orion Model 290 A Plus pH meter with glass and reference electrodes was used and the $\mathrm{pH}$ of each reaction mixture, measured at the start and end of each reaction, held constant.

All spectral and kinetic measurements were performed in a $1 \mathrm{~cm}$ cell under Peltier temperature control using an Agilent Model 8453 uv/vis spectrophotometer. The increase of the product $\mathrm{Ni}$ (bipy) 3 absorbance was followed at $307 \mathrm{~nm}$ because this wavelength showed the greatest change in molar absorptivity between reactants and products. At this wavelength, the values of the molar absorptivities $\left(\mathrm{M}^{-1} \mathrm{~cm}^{-1}\right)$ are listed in Table 1.

Table 1. Molar absorptivities of reacting species at $307 \mathrm{~nm}$.

\begin{tabular}{|c|c|}
\hline Compound & $\begin{array}{c}\text { Molar Absorptivity, } \varepsilon \\
\mathbf{M}^{-1} \mathrm{~cm}^{-1}\end{array}$ \\
\hline $\mathrm{Ni}(\text { bipy })_{3}$ & $3.41 \times 10^{4}$ \\
\hline Ni(NT A)(bipy) & $1.22 \times 10^{4}$ \\
\hline $\mathrm{Hbipy}^{+}$ & $1.01 \times 10^{4}$ \\
\hline Bipy & $4.75 \times 10^{2}$ \\
\hline NiNTA- & 22.3 \\
\hline
\end{tabular}

Taking into account the absorbances of all species at both time $t$ and time infinity, the concentration of $\mathrm{NiNTA}^{-}$at time $t$ can be computed using the following equation:

$$
\text { [Ni(NTA)(bipy)] }
$$

$\frac{\mathrm{A}_{\infty}-A_{\mathrm{t}}}{\mathrm{b}\left(\varepsilon_{\mathrm{Ni}(\text { bipy })_{3}}-2 \varepsilon_{\text {bipy }}-2\left[\mathrm{H}^{+}\right] \frac{\varepsilon_{\mathrm{Hbipy}}}{\mathrm{K}_{\mathrm{a}}}-\varepsilon_{\mathrm{Ni}(\mathrm{NTA})(\text { bipy })}\right)}$

In equation (4), the two terms in the numerator represent absorbance values of $\mathrm{Ni}$ (bipy) 3 at time infinity and at time $\mathrm{t}$ whereas in the denominator, $b$ is the pathlength, and the other terms represent the molar absorptivities of each respective species. The lower $\mathrm{pH}$ limit for data collection is around 4.7 because below this value, small absorbance changes were measured due to the high molar absorptivity of $\mathrm{Hbipy}^{+}$. In addition, the faster reactions made data collection less reproducible.

\section{Results}

The NiNTA- -bipy ligand exchange reaction occurs in two main steps as shown above in (1) and (2) with $\mathrm{L}=\mathrm{NTA}$ and $\mathrm{B}_{2}$ $=$ bipy. The overall exchange reaction is given by:

$(5) \mathrm{Ni}(\mathrm{NTA})\left(\mathrm{H}_{2} \mathrm{O}\right)_{2}{ }^{-}+3$ bipy $\rightarrow \mathrm{Ni}(\text { bipy })_{3}+\mathrm{NTA}^{3-}+2 \mathrm{H}_{2} \mathrm{O}$

in which the two coordinated water molecules occupy cis positions in $\operatorname{NiNTA}\left(\mathrm{H}_{2} \mathrm{O}\right)_{2}{ }^{-}$. The experimental data is summarized in Table 2 where each reported rate constant along with its standard deviation represents the average of three to five runs, expect for the rate constant marked with an asterisk which was obtained from duplicate runs.

Table 2. First-order rate constants for the NiNTA-bipy reaction at $25.0{ }^{\circ} \mathrm{C}, \mu=0.10 \mathrm{M}$ where $\left[\mathrm{NiNTA}^{-}\right]=2.01 \times 10^{-5}$ M.

\begin{tabular}{|c|c|c|c|c|c|}
\hline pH & $\begin{array}{c}10^{4}[\mathrm{~b} \dot{\text { py }}]_{0} \\
\text { M }\end{array}$ & $\begin{array}{c}10^{4} k^{0} \\
s^{-1}\end{array}$ & pH & $\begin{array}{c}10^{4}[\text { bipy }]_{0} \\
\text { M }\end{array}$ & $\begin{array}{c}10^{4} \mathrm{k}^{0} \\
\mathrm{~s}^{-1}\end{array}$ \\
\hline 7.507 & 4.18 & $2.61+0.13$ & 6.010 & 12.54 & $6.89+0.18^{*}$ \\
\hline 7.250 & 4.18 & $2.70 \pm 0.070$ & 5.757 & 4.18 & $3.24 \pm 0.089$ \\
\hline 7.002 & 4.18 & $2.67 \pm 0.044$ & 5.502 & 4.18 & $3.57 \pm 0.18$ \\
\hline 6.250 & 4.18 & $2.81+0.007$ & 5.250 & 4.18 & $4.20+0.27$ \\
\hline 6.026 & 4.18 & $3.09 \pm 0.10$ & 5.010 & 4.18 & $4.82 \pm 0.11$ \\
\hline 6.020 & 8.36 & $5.07 \pm 0.13$ & 4.767 & 4.18 & $6.31 \pm 0.56$ \\
\hline 6.020 & 10.6 & $5.92 \pm 0.11$ & & & \\
\hline
\end{tabular}

For all kinetic runs listed in Table 2, the initial bipyridine concentrations [bipy $]_{0}$ represent the total initial values while the $\mathrm{NiNTA}^{-}$concentration was held constant at $2.01 \times 10^{-5} \mathrm{M}$. Pseudo-first-order conditions were employed with at least a 20 fold excess of [bipy] over [NiNTA ${ }^{-}$. All reactions were followed to at least $90 \%$ completion.

If the reaction is first-order in NiNTA', then at constant $\mathrm{pH}$, the following rate equation holds using the fact that [bipy $]_{0}$ $>$ [NiNTA']:

(6) Rate $=-\frac{\mathrm{d}[\mathrm{Ni}(\mathrm{NTA})(\mathrm{bipy})]}{\mathrm{dt}}=\frac{\mathrm{d}\left[\mathrm{Ni}(\mathrm{bipy}]_{3}\right]}{\mathrm{dt}}=\mathrm{k}^{0}[\mathrm{Ni}(\mathrm{NTA})($ bipy $)]$

www.jofsr.com 
where $\mathrm{k}^{0}=\mathrm{k}$ [bipy $]_{0}$ is the pseudo-first-order rate constant and $\mathrm{k}$ is the second-order rate constant. When equation (6) is integrated, a plot of $\log \left[\mathrm{Ni}(\text { bipy })_{3}\right]$ versus time gave a straight-line of slope $\mathrm{k}^{0}$. All plots, such as the one shown in Figure 1, were linear over three half lives, establishing the reactant order in $\left[\mathrm{NiNTA}^{-}\right]$as one.

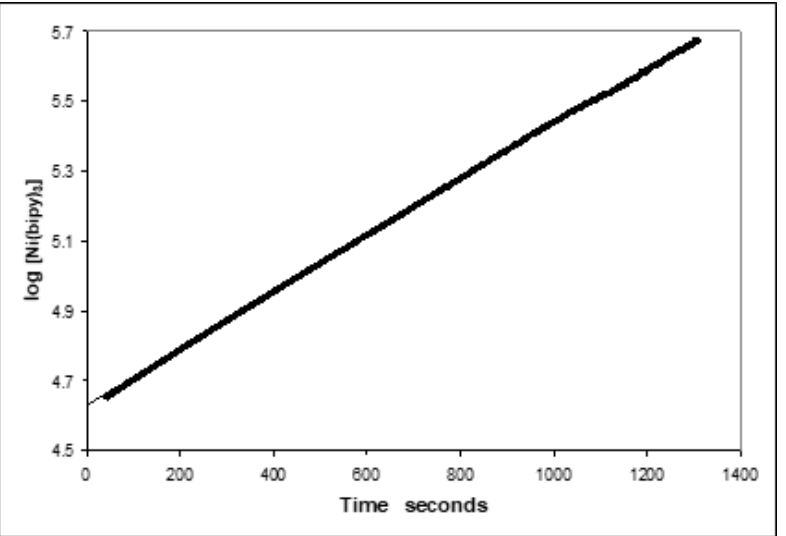

Figure 1. Plot of $\left.\log [\mathrm{Ni} \text { (bipy) })_{3}\right]$ vs. time at $\mathrm{pH}$ 5.50. Bold line represents collected data points.

The absence of biphasic behavior in these first-order plots indicates the presence of NiNTA- as the only reactant.

Having established first-order behaviour with respect to NiNTA ${ }^{-}$, the dependence of $\mathrm{k}^{0}$ on bipyridine concentration was studied. In solution, bipyridine can exist in unprotonated (bipy), mono-protonated $\left(\mathrm{Hbipy}^{+}\right)$or diprotonated $\left(\mathrm{H}_{2} \mathrm{bipy}^{2+}\right)$ forms. In the $\mathrm{pH}$ range studied, the diprotonated form is of negligible concentration. Further, because of the flexibility of bipy, the possibility exists that both the mono- and diprotonated forms may react with NiNTA'.

To find the concentration of free bipy available to react with $\mathrm{NiNTA}^{-}$, the total initial bipyridine concentration [bipy $]_{0}$ , as given in Table 2, must be corrected for the amount lost in forming the ternary complex through the equation:

(7) $[\text { bipy }]_{\text {free }}=[\text { bipy }]_{0}-\left[\mathrm{NiNTA}^{-}\right]_{0}=\left[\mathrm{Hbipy}^{+}\right]+[$bipy $]$

where [bipy]free expresses the available bipy partitioned between the mono- and un-protonated forms. The dependence of $\mathrm{k}^{0}$ on [bipy] was studied using four runs at $\mathrm{pH} 6.0$ and the corresponding data is given in Table 2. A plot of $\mathrm{k}^{0}$ vs [bipy], where bipy concentrations were calculated via a distribution diagram, is displayed in Figure 2. The plot is linear, indicating a first-order dependence on the monoprotonated form of bipy.

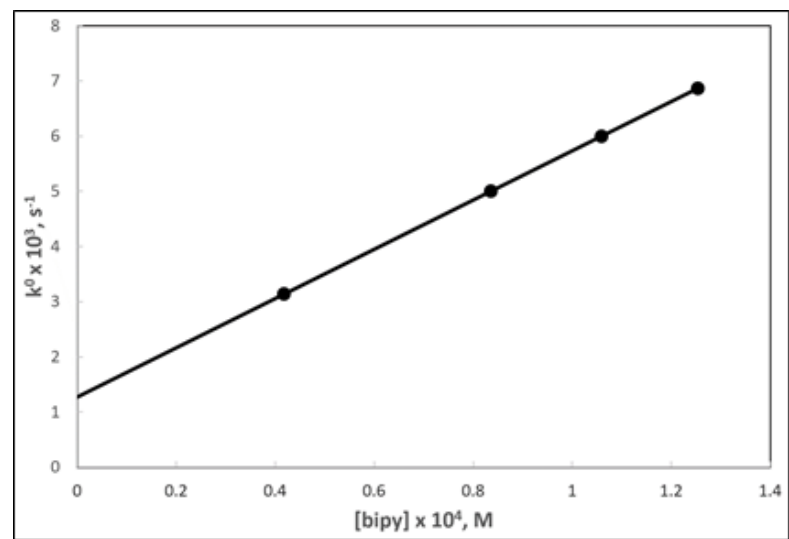

Figure 2. Plot of $\mathrm{k}^{0}$ vs. [bipy] at $\mathrm{pH}$ 6.0.

Experiments also demonstrated that the reaction rate decreased as the $\mathrm{pH}$ increased as shown by the plot of $\mathrm{k}^{0}$ versus $\mathrm{pH}$ in Figure 3.

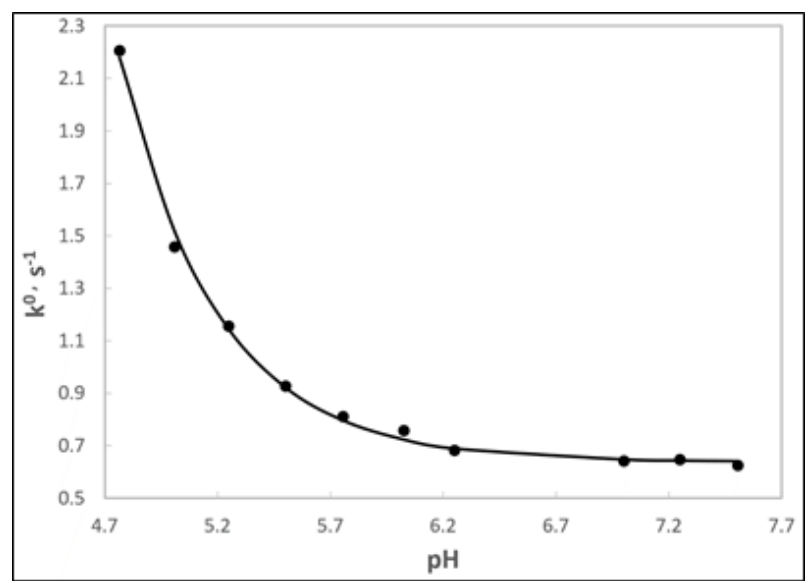

Figure 3. Dependence of rate constant $\mathrm{k}^{0}$ on $\mathrm{pH}$.

Assuming that both mono- and di-protonated bipy species are able to react with NiNTA', the second-order rate constant can be written as a two term function in bipy and Hbipy ${ }^{+}$.

(8) $\mathrm{k}^{0}=\mathrm{k}_{\text {bipy }}^{\text {Ni(NTA)bipy }}{ }^{\text {bipy }]}+\mathrm{k}_{\text {Hbipy }^{+}}^{\text {Ni(NTA)bipy }}{ }_{\left[\mathrm{Hbipy}^{+}\right]}$

Substituting for $\left[\mathrm{Hbipy}^{+}\right]$using its first acid dissociation constant $\mathrm{K}_{\mathrm{a}}$ gives:

(9) $\mathrm{k}^{0}=\mathrm{k}_{\text {bipy }}^{\mathrm{Ni(NTA)bipy}}[$ bipy $]+\frac{\mathrm{k}_{\text {Hbipy }^{+}}^{\mathrm{Ni(NTA)bipy}}\left[\mathrm{H}^{+}\right][\text {bipy }]}{\mathrm{K}_{\mathrm{a}}}$

Rearranging (8) allows the hydrogen ion dependence to be resolved:

(10) $\mathrm{k}=\frac{\mathrm{k}^{0}}{[\text { bipy }]}=\mathrm{k}_{\mathrm{bipy}}^{\mathrm{Ni}(\mathrm{NTA}) \text { bipy }}+\mathrm{k}_{\mathrm{Hbipy}}^{\mathrm{Ni(NTA)bipy}}\left[\mathrm{H}^{+}\right]$ 
where $\mathrm{k}$ is the second-order rate constant and $\mathrm{k}_{\mathrm{H}, \text { bipy }}^{\text {Ni(NTA)bipy }}=\frac{\mathrm{k}_{\text {Hbipy }^{+}}^{\text {Ni(NT)bipy }}}{\mathrm{K}_{\mathrm{a}}}$.

All the experimental data, including runs representing both constant $\mathrm{pH}$ and varying bipyridine concentrations are plotted together according to equation (9) in Figure 4. The bipyridine concentrations used in the plot were computed using the fraction of bipyridine existing in the unprotonated form using published $\mathrm{pK}_{\mathrm{b}}$ values ${ }^{21}$.

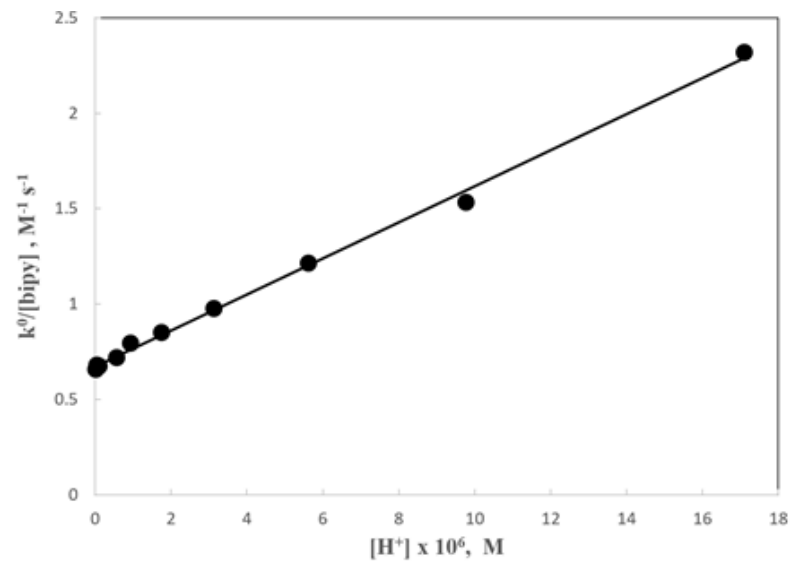

Figure 4. Resolution of proton dependent- and independentrate constants.

The graph is linear over four orders of magnitude in hydrogen ion concentration with a correlation coefficient of 0.998 . The slope obtained from the $\mathrm{k}^{0}$ versus $\left[\mathrm{H}^{+}\right]$plot gives the proton dependent addition of bipy to NiNTA, denoted by $\mathrm{k}_{\mathrm{H} \text {,bipy }}^{\mathrm{Ni}(\mathrm{NTA}) \text { bipy }}$, while the intercept given by $\mathrm{k}_{\text {bipy }}^{\mathrm{Ni(NTA)bipy}}$,

Table 3. Resolved rate constants for the reactions of $X=$ phen or bipy with NiLX where $\mathrm{L}=\mathrm{NTA}^{-}, \mathrm{EDDA}$ or tetren represents the hydrogen ion independent addition of bipy to NiNTA. A summary of the experimentally determined rate constants and those of similar reactions is provided in Table 3.

\begin{tabular}{|lcc|}
\hline & $\begin{array}{c}\mathrm{k}_{\mathrm{H}, \mathrm{X}}^{\mathrm{NiX}} \\
\mathrm{M}^{-2} \mathrm{~s}^{-1}\end{array}$ & $\begin{array}{c}\mathrm{k}_{\mathrm{X}}^{\mathrm{NiLX}} \\
\mathrm{M}^{-1} \mathrm{~s}^{-1}\end{array}$ \\
\hline NiNTA-bipy & $(9.45+0.0017) \times 10^{4}$ & $0.672+0.011$ \\
NiEDDA-phen & $(5.17 \pm 0.16) \times 10^{3}$ & $(7.84 \pm 0.18) \times 10^{-2}$ \\
Nitetren-bipy & $2.27 \times 10^{6} \pm 5.7 \times 10^{4}$ & $-0.29 \pm 0.31$ \\
Rate constant ratio & 18.3 & 8.6 \\
(NiNTA/NiEDDA) & & \\
(Nitetren/NiNTA) & 25.2 & Not applicable \\
\hline
\end{tabular}

\section{Discussion}

If in the initial nickel complex, NTA completely decoordinated before bipy attacked, then the order in bipy would be zero. However, since the reaction is first-order in bipy, the general mechanism must involve bipy attacking a partly decoordinated
NTA which is subsequently displaced. Therefore the rate determining step must occur after at least one bipy coordinates in the ternary complex and before the fast addition of the third bipy to form $\mathrm{Ni}$ (bipy)3. The proposed mechanism, shown in Figure 5, is similar to that reported for the NiEDDA-phen reaction and the rate determining step given by $5 \rightarrow 6$, most likely involves the breakage of the nickel-glycinate bond in intermediate 5 .

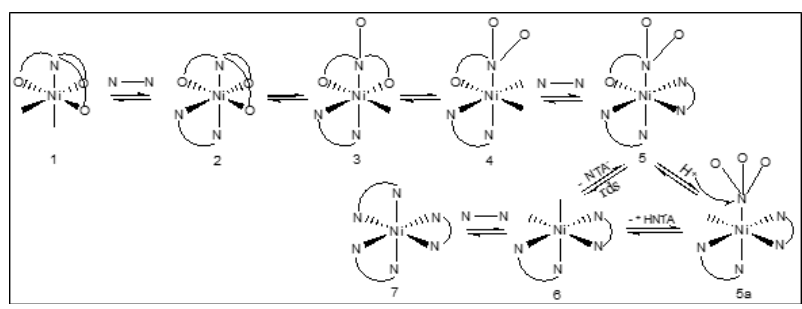

Figure 5. General mechanism for the ligand exchange reaction between bipy and NiNTA:

The increased rate at lower $\mathrm{pH}$ values is attributed to protonation of a partly detached NTA segment that is then unable to recoordinate to nickel. This process is shown in step $5 \rightarrow 5$ a of Figure 5. As in the NiEDDA-phen system, at lower $\mathrm{pH}$ values, the more basic nitrogen of the aminocarboxylate protonates first while accelerating the dissociation of the nickel complex.

The $\mathrm{k}_{\mathrm{H} \text {,bipy }}^{\mathrm{Ni} \text { (NTA)bipy }}$ term is about 20 times higher than the corresponding rate constant for the NiEDDA-phen reaction. Further, the proton unassisted rate constant for the NiNTAbipy reaction is about 8 times higher than that for the NiEDDAphen reaction, as given in Table 3 .

These differences are attributed to the more flexible attacking bipy, the more labile NiNTA, and greater steric hindrance in NiEDDA. It is possible to predict ${ }^{23}$ the $2^{\text {nd }}$ order rate constant $\mathrm{k}_{56}$ describing the proton unassisted addition of bipy to NiNTA by using the equation:

(11) $\mathrm{k}_{\text {bipy }}^{\text {Ni(NTA)bipy }}=\frac{\mathrm{K}_{\mathrm{Nigly}^{+}} \mathrm{K}_{\text {Nibipy }}}{\mathrm{K}_{\mathrm{NiNTA}}} \mathrm{K}_{\mathrm{el}} \mathrm{k}_{\mathrm{Nigly}}$

The first factor in (11) takes into account the stability of intermediate 5 relative to that of the initial complex. The $\mathrm{K}_{\mathrm{el}}$ term $^{24}$ describes the contribution of the electrostatic attraction of complexed nickel ion for glycinate, which helps stabilizes intermediate 5 , while the $\mathrm{k}_{\text {Nigly }}$ term is the rate constant for the dissociation of glycinate from nickel. Using these values published by Martell and $\mathrm{Smith}^{25}$ : $\mathrm{K}_{\mathrm{Nigly}^{+}}=1.95 \times 10^{5}$, $\mathrm{K}_{\text {Nibipy }}=1.05 \times 10^{7}, \mathrm{~K}_{\text {NiNTA }}=3.16 \times 10^{11}$ and this value by Hammes $^{26}: \mathrm{k}_{\text {Nigly }}=0.024 \mathrm{~s}^{-1}$ along with a calculated value of $\mathrm{K}_{\mathrm{el}}=3.2$ by Bydalek $^{10}$, gives a predicted value of $\mathrm{k}_{\text {bipy }}^{\mathrm{Ni}(\mathrm{NTA}) \text { bipy }}=0.50 \mathrm{M}^{-1} \mathrm{~s}^{-1}=\mathrm{k} 56$ which compares favorably with the measured value of $0.672 \mathrm{M}^{-1} \mathrm{~s}^{-1}$.

In conclusion, the kinetic behavior of the NiNTA-bipy reaction is very similar to that reported for the NiEDDA-phen reaction with proton assisted pathway dominant. Moreover, the NiNTA rate constants for proton assisted and non-assisted pathways are much higher, by a magnitude of ten. These results indicate that changing the bidentate ligand from phen to 
bipy while increasing the number of labile dentate sites from two to three on going from EDDA to NTA, does not alter the mechanism which may therefore be of general utility for all aminopolycarboxylate nickel(II) complexes. However, the straight chain polyamine nickel complex of tetren is faster so that the reaction rate follows the order: NiEDDA $<\mathrm{NiNTA}^{-}<$ Nitetren, with the latter complex reacting about 25 times faster than NiNTA- The Nitetren reaction differs from the aminopolycarboxylate reactions in that it has only has a proton assisted pathway. Further work is underway to examine the reactions of bipy with Nitrien ${ }^{2+}$ and $\mathrm{Nitren}^{2+}$.

\section{Acknowledgements}

This work was supported by the Eastern Michigan University Chemistry Department and a Chrysler Grant. We also thank students Nekuma Hollis and Jay Schmitt for contributing to this project.

\section{References}

1. Ralph G. Wilkins, Accounts Chem. Res., 3, 408 (1970).

2. D. W. Margerum, G. C. Cayley, D. C. Weatherburn, and G. K. Pagenkopf, Coordination Chemistry", A. E. Martell, Ed., American Chemical Society, Washington, D.C., 1978, ACS Mongr. No. 174, pp. 106-194.

3. R. K. Steinhaus and L. H. Kolopajlo, Inorg. Chem. 24, 1839 (1985).

4. R. K. Steinhaus and L. H. Kolopajlo, Inorg. Chem. 24, 1845 (1985).

5. R. K. Steinhaus and B. I. Lee, Inorg. Chem. 21, 1829 (1982). 6. D. W. Margerum, G. C. Cayley, D.C. Weatherburn, G.K. Pagenkopf, ACS Monograph No. 174, (1978), pp. 1-87.

7. R. K. Steinhaus, Inorganica Chimica Acta, 63, 1, (1982).

8. R. K. Steinhaus and J. A. Boersma, Inorg. Chem., 11, 7, 1505, (1972).

9. James C. Cassatt, William A Johnson, Lloyd M Smith and Ralph G Wilkins, J. Am. Chem. Soc, 94:24, 8399 (1972).

10. T. J. Bydalek and M. L. Bloomster, Inorg. Chem., 3, 667 (1964).

11. Brewer, Timothy R.; Mattieson, Mace; Kolopajlo, Larry. J. Coord. Chem. 2003, 56 (10), 851-860.
12. Kolopajlo, Lawrence Hugh; Hollis, Nekuma; Pendelton, Ian. Journal of Student Research, 2012, 2: 39-45.

13. Nitrilotriacetic acid. Detergents

https://pubchem.ncbi.nlm.nih.gov/compound/8758\#section=S afety-and-Hazards (accessed on june 20, 2017.)

14. Fang-Chih, C.; Ya-Nang, W.; Pin-Jui, C.; Chun-Han, K. J. Environ. Manag. 2013, 122, 42-46.

15. Nrigau, Jerome O. (Ed,) Nickel in the Environment. John Wiley \& Sons, New York 1980.

16. Cempel, M; Nikel, G. Polish J. of Environ. Stud. Vol. 15, No. 3 (2006), 375-382.

17. Nitrilotriacetic acid.

https://pubchem.ncbi.nlm.nih.gov/compound/8758\#section=S afety-and-Hazards

(accessed on june 20, 2017.)

18. Nickel. http://www.espimetals.com/index.php/msds/221Nickel. (accessed June 20, 2017).

19. Sodium cyanide. http://www.sigmaaldrich.com/MSDS/MSDS/DisplayM SDSPage.do?country=US\&language $=$ en $\&$ productNum ber $=205222 \&$ brand $=$ SIGALD\&PageToGoToURL $=\mathrm{htt}$ p $\% 3 \mathrm{~A} \% 2 \mathrm{~F} \% 2 \mathrm{Fwww}$.sigmaaldrich.com\%2Fcatalog $\% 2$ Fproduct $\% 2$ Fsigald $\% 2$ F205222\%3Flang\%3Den (accessed June 22, 2017).

20. Steinhaus, R. K.; Swann, R. L. Inorg. Chem., 1972, 12 (8), 1855-1860.

21. Martell, Arthur E. "Critical Stability Constants: Amines", Volume 2, Plenum Press, New York, 1974.

22. D. B. Rorabacher and D. W. Margerum, Inorg. Chem., 3, 382 (1963).

23. T. J. Bydalek and D. W. Margerum, Inorg. Chem., 2, 678 (1963).

24. A. E. Martell and R. M. Smith, "Critical Stability Constants", Vol. 1 - 5, Plenum Press, New York, 1974.

25. G. G. Hammes and J. I. Steinfield, J. Am. Chem. Soc., 84, 4639 (1962) 